\title{
Mass mortality event of the blood cockle, Anadara granosa, in aquaculture ground along Selangor coast, Peninsular Malaysia
}

\author{
Tatsuya Yurimoto • Faizul Mohd Kassim • \\ Reiko Fuseya $\cdot$ Alias Man
}

Received: 22 June 2014/ Accepted: 2 September 2014/Published online: 20 September 2014

(C) The Author(s) 2014. This article is published with open access at Springerlink.com

\begin{abstract}
A mass mortality event of blood cockles, Anadara granosa, occurred in aquaculture ground in Selangor in mid-February 2012. To identify factors contributing to this event, we estimated the changes in survival rate and population density of the blood cockles using data from field surveys carried out in lateJanuary and mid-March, 2012. In addition, blood cockle samples were used for histological observation of various tissues with a light microscope. Furthermore, we examined the environmental factors that seemed to be involved in this mass mortality event using environmental data obtained in two surveys and weather data for the Selangor region from late-January to mid-March 2012. As a result of the field surveys and the histological observation, the mortality was estimated to be $30 \%$ over, and the blood cockles were shown to be in the spawning season at this time of year. In addition, numerous individuals collected in mid-March had no food in the digestive duct, which suggested low food availability. Precipitation data for the Selangor region showed rainfall of $30 \mathrm{~mm} /$ day over four days in mid-February, which suggested an impact of freshwater flooding from rivers on the aquaculture ground. Normally, the blood cockles are tolerant to low-salinity environments. However, the fact that the flooding and associated environmental changes occurred, when the population was debilitated by reproductive activity, may have led to the mass mortality event in association with low food availability.
\end{abstract}

Keywords Blood cockle $\cdot$ Anadara granosa $\cdot$ Mass mortality $\cdot$ Malaysia

\section{Introduction}

The blood cockle, Anadara granosa, is a member of the Arcidae family and has red bodily fluid that contains hemoglobin, like blood. This species is widely distributed, from the Middle East to East Asia (Faulkner 2010).

T. Yurimoto $(\bowtie)$

Japan International Research Center for Agricultural Sciences, Tsukuba, Ibaraki 305-8686, Japan

e-mail: yurimoto@outlook.com

F. Mohd Kassim

Penang Office of Japan International Research Center for Agricultural Sciences, 11960 Batu Maung, Penang, Malaysia

R. Fuseya

National Research Institute of Fisheries Engineering, Fisheries Research Agency, Kamisu, Ibaraki 314-0408, Japan

A. Man

Fisheries Research Institute, Department of Fisheries, 11960 Batu Maung, Penang, Malaysia 
Its habitat is soft muddy bottoms of tidal flats formed in estuaries or the interior of bays (Narashimham et al. 1984; Nakao et al. 1989). It is also a major aquaculture species, with Malaysia and Thailand being among the Southeast Asian countries that have been actively developing its use in this field (Watanabe 2009). In particular, in the Selangor region of Malaysia, blood cockle aquaculture is flourishing because a large number of juvenile cockles naturally develop in the tidal flats of this region, and many of them are collected for aquaculture. These juveniles have been supplied as seeds for aquaculture grounds in not only the Selangor region but also surrounding areas.

The harvest of blood cockles in the Selangor region remained at less than 10,000 tons in the early 2000s, but increased after 2008, with a record harvest of about 40,000 tons in 2010. Factors thought to have contributed to this increase include the arrival of new aqua farmers and expansion of the area used for aquaculture. However, the harvest has declined to about 25,000 tons since 2011, with its level remaining unstable (Alias Man, unpublished data). Factors that may have had an impact on this have been identified, such as overcrowding cockles, sediment deterioration, flooding, and sediment disturbance in aquaculture grounds, but the main factor remains unidentified. Against this background, we heard from fishermen that a mass mortality event of blood cockles occurred at our monitoring site for aquaculture research in Selangor in mid-February, 2012. To achieve stable production in bivalve aquaculture, it is important to measure and control factors that negatively influence the growth of these organisms. Therefore, in order to clarify the causes of this mass mortality event, we examined the survival rate and population density of the cockles, alongside an environmental survey using data from field surveys that were conducted before and after the mass mortality event; in addition, the blood cockles were observed histologically after the two sampling periods, and the obtained results were discussed along with data on the weather at around this time.

\section{Materials and methods}

Sample collection

On January 30 and March 15, 2012, field surveys were carried out in a blood cockle aquaculture ground along the coast of Selangor (Fig. 1). To collect blood cockles, we performed quantitative sampling used a long hand dredge (basket size: $60 \mathrm{~cm}$ wide, $15 \mathrm{~cm}$ high, $30 \mathrm{~cm}$ deep) with a $1.5 \mathrm{~cm}$ mesh. The towing distance of this dredge was estimated from the hauling time and the navigation speed of the fishing boat to determine the collection area, and we calculated the population density of blood cockles in the aquaculture ground. In addition, the collected blood cockles were measured in terms of the shell length of each individual.

\section{Histological observation}

The collected blood cockles were brought back to a laboratory, and the interior of each organism was excised to produce tissue blocks of the various organs (gill, mantle, digestive gland, and gonads) after measurement of the shell length. These blocks were immersion fixed in $10 \%$ formalin seawater solution. Fixed tissue was then embedded in paraffin to make a paraffin block after alcohol dehydration and lemosol replacement. The paraffin block was cut into thin sections 5-10 $\mu \mathrm{m}$ thick with a microtome, and the tissue was observed under a light microscope after hematoxylin \& eosin staining. The various tissues were observed and the presence or absence of lesions, parasites, and food in the digestive duct were estimated.

\section{Environment}

The environmental features of the blood cockle aquaculture ground were examined by field sampling. Using a throw-in-type water-quality sensor (AAQ-RINKO, JFE Advantech Co., Ltd., Japan), water-quality parameters, such as temperature, salinity, dissolved oxygen, and chlorophyll- $a$ concentration, were measured at a layer $20 \mathrm{~cm}$ from the bottom at the survey site. In addition, surface mud was collected with an Ekman-Barge bottom sampler at the survey site, and redox potential and $\mathrm{pH}$ of the surface sediments $(0-1 \mathrm{~cm})$ were measured. In addition, to clarify the relationship between weather and the mass mortality event, we obtained 
Fig. 1 Sampling location (asterisk) of blood cockles, Anadara granosa, at an aquaculture ground in the Selangor region, Malaysia, at which a mass mortality event occurred

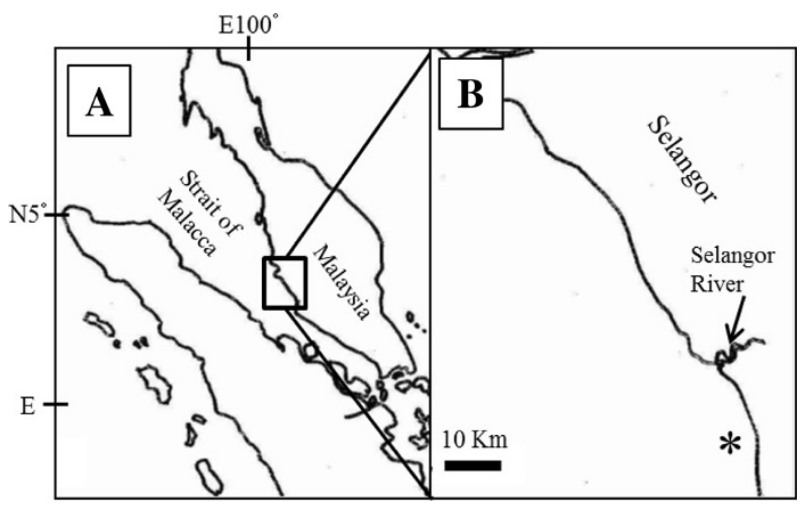

Table 1 Details of the sampling of blood cockles, Anadara granosa, collected in an aquaculture ground along the Selangor coast in late-January and mid-March, 2012

\begin{tabular}{lllllll}
\hline Date & $\begin{array}{l}\text { Hauling area of } \\
\text { dredge net }\left(\mathrm{m}^{2}\right)\end{array}$ & Total number of individuals & $\begin{array}{l}\text { Status of } \\
\text { individuals }\end{array}$ & & Mortality rate $(\%)$ & $\begin{array}{l}\text { Density of alive } \\
\text { individuals }\left(/ \mathrm{m}^{2}\right)\end{array}$ \\
\cline { 3 - 6 } & & Alive & Dead & & \\
\hline 30th Jan., 2012 & 54 & 422 & 420 & 2 & $<0.5$ & 7.8 \\
15th Mar., 2012 & 27 & 191 & 129 & 62 & 32.5 & 4.8 \\
\hline
\end{tabular}

rainfall data in the Selangor region from January to March, 2012, from the Water Resources Management and Hydrology Division, Department of Irrigation and Drainage, Malaysia.

\section{Results}

Mortality and population density

The population density (number of individuals per sampling area) of the blood cockles was calculated for each set of sampling data for late-January and mid-March. The density decreased from 7.8 to $4.8 / \mathrm{m}^{2}$ over these two sampling dates (Table 1). In addition, the dead individual, it was showed no closed shells reaction upon stimulation or eluted molluscous part remained the shells, and the percentage among the collected blood cockle samples was less than $0.5 \%$ in late-January, but rose to $32.5 \%$ in mid-March (Table 1).

Shell length

The shell length histogram of the collected blood cockles was compared between late-January and mid-March (Fig. 2). The two sets of data exhibit single peaks: at $28 \mathrm{~mm}$ in late-January and $30 \mathrm{~mm}$ in mid-March. In addition, we also plotted the distribution of shell length of dead individuals collected in the survey in midMarch. A single peak was again shown, the same as for the other results. However, this peak was at $27 \mathrm{~mm}$.

\section{Parasitism}

Parasite infection status was evaluated for the gonads $(n=30)$ and digestive gland $(n=24)$ in late-January, and for the gonads $(n=30)$, digestive gland $(n=24)$, mantle $(n=18)$, and gill $(n=18)$ in mid-March. However, parasites were not observed in these tissues. 
Fig. 2 Shell length distribution of blood cockles, Anadara granosa, collected at an aquaculture ground along Selangor coast in late-January and mid-March, 2012. a Shell length distribution in late-January. b Shell length distribution in mid-March. c Shell length distribution of dead individuals in mid-March

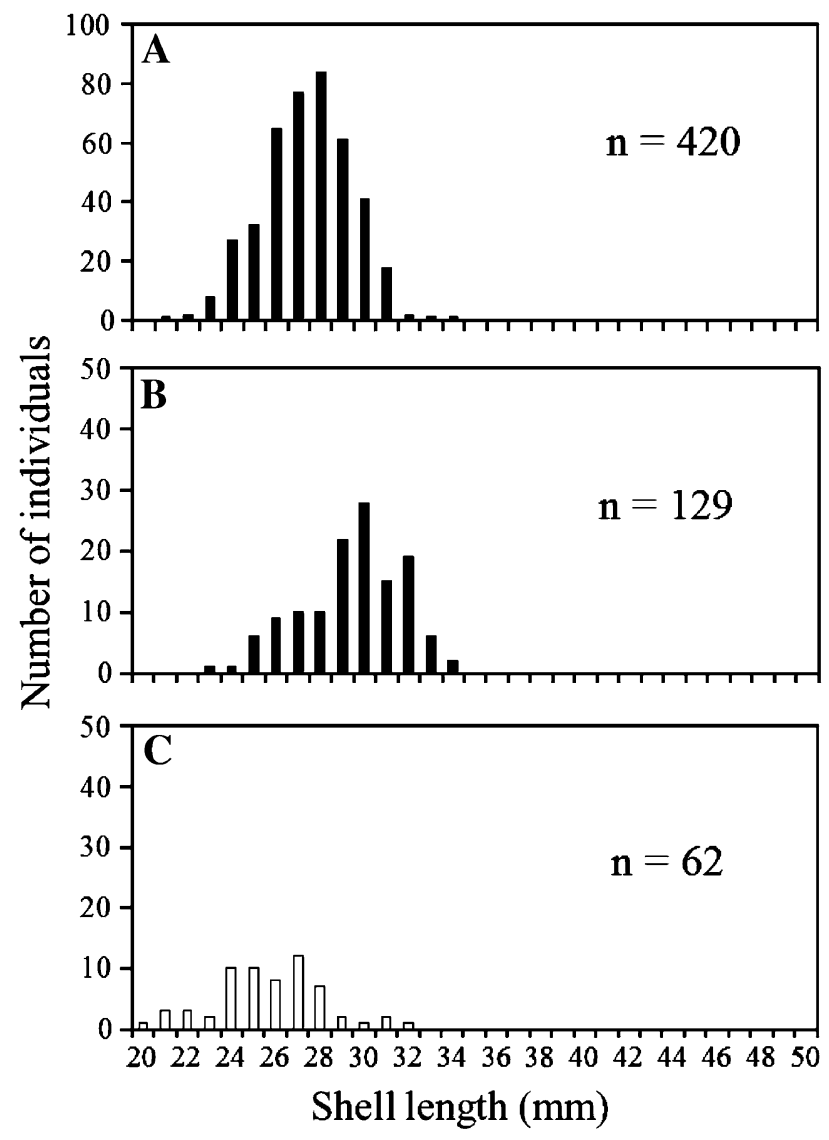

Gonads

In accordance with the classification of gonad development in previous reports on blood cockles (Yurimoto et al. 2008, 2014), individuals of both sexes in the mature stage/spawning stage (stages III-IV) dominated, while some females had already reached the spent stage (stage V) in late-January (Fig. 3). Although individuals of both sexes in stage III or IV were still observed in March, they were less dominant and the number in stage $\mathrm{V}$ had increased.

Digestive gland

To clarify the status of food availability for the blood cockles, we observed food content in the digestive duct and the tissue condition of the digestive tube. Epithelial cell condition in the digestive tube was classified into three categories: Class I represents good condition of epithelial cells, with large cell length and high cell density (Fig. 4I). Class II represents an intermediate condition of the epithelial cells, with reduced cell length and spaces being observed in the gland (Fig. 4II). Class III represents a worse condition of the epithelial cells, with the conditions described for class II being observed over a wide area of the digestive gland and the gland being thinner (Fig. 4III). The obtained results are shown in Fig. 5. In late-January, individuals categorized into class I accounted for more than $40 \%$ of the total, but this proportion decreased to about $20 \%$ in March.

Food availability

The digestive duct in the digestive gland was observed to estimate food intake. For the tissue sections of individuals who had been feeding, the digestive duct filled with fine particles, including diatoms, could be seen (Fig. 6a). On the other hand, such fine particles were not observed for individuals who had not been feeding sufficiently (Fig. 6b). The difference in this characteristic between late-January and mid-March is summarized 
Fig. 3 Ratio of maturation stages of blood cockles, Anadara granosa, collected at an aquaculture ground along Selangor coast in late-January and mid-March, 2012. III Mature stage. IV Spawning stage. $V$ Spent stage. a Male. b Female

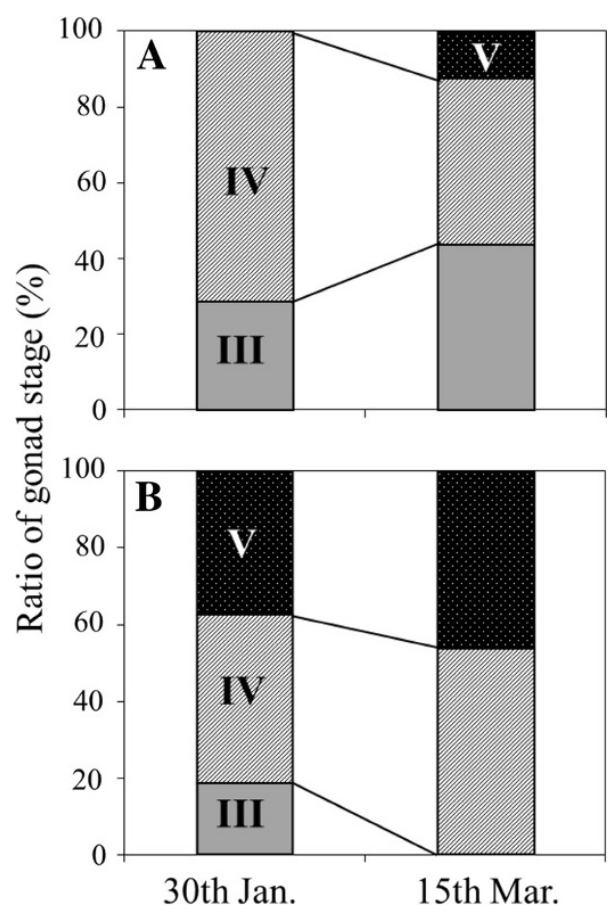

in Fig. 7. Food intake was observed in more than $60 \%$ of individuals in late-January, but this rate decreased to about $20 \%$ in mid-March.

\section{Environment}

The results of environmental measurement of water temperature, salinity, dissolved oxygen, and chlorophyll$a$ concentration in the bottom layer and redox potential and $\mathrm{pH}$ in surface sediments in late-January and midMarch are summarized in Table 2. No parameter showed a significant difference between the two periods. The level of chlorophyll- $a$ was about $5 \mu \mathrm{g} / \mathrm{L}$ in both months, the $\mathrm{pH}$ in surface sediments was 7.4-7.5, and the redox potential showed an oxidation state of over $60 \mathrm{mV}$ in late-January and mid-March.

\section{Weather}

Daily precipitation in the Selangor estuary in January-March 2012 is shown in Fig. 8. The monthly amounts in January and March were lower than that in February; a rate of over $30 \mathrm{~mm} /$ day occurred on only one day in each of these two months. In contrast, such a rate was observed on four near-consecutive days during midFebruary. In particular, on the 15th of February, the level exceeded $50 \mathrm{~mm} /$ day.

\section{Discussion}

There are many reports about mass mortality events in bivalves, such as pen shell, ark shell, Pacific oyster, and pearl oyster (Imai et al. 1969; Tomaru et al. 2001; Nakamura 2005; Maeno et al. 2006). Normally, an emergency survey or research on such events is conducted a thorough investigation to determine the cause because they can lead to major economic losses in the bivalve aquaculture industry. However, identification of the main causative factors is extremely difficult because these events involve a complicated interplay between the physiological condition of bivalves and environmental factors, so the cause of death can rarely be explained by a single factor. For example, even when bivalves are exposed to poor environmental conditions, such as hydrogen sulfide or hypoxia, they exhibit some resistance and do not die straight away (Nagasoe et al. 2011; Suzuki et al. 2012). For this reason, when a mass mortality event occurs, if the environment of fishing grounds is investigated after a mass mortality event occurs, it is difficult to identify the causative factor 
Fig. 4 Microphotographs of the digestive gland of blood cockles, Anadara granosa, collected at an aquaculture ground along Selangor coast in late-January and midMarch, 2012. I Good condition of epithelial cells. II Partial flattening of epithelial cells (arrows). III Substantial flattening of epithelial cells (arrows). Scale bar represents $100 \mu \mathrm{m}$
Fig. 5 Ratios of the digestive gland condition of blood cockles, Anadara granosa, collected at an aquaculture ground along Selangor coast in late-January and midMarch, 2012. I Good condition of epithelial cells. II Partial flattening of epithelial cells. III Substantial flattening of epithelial cells
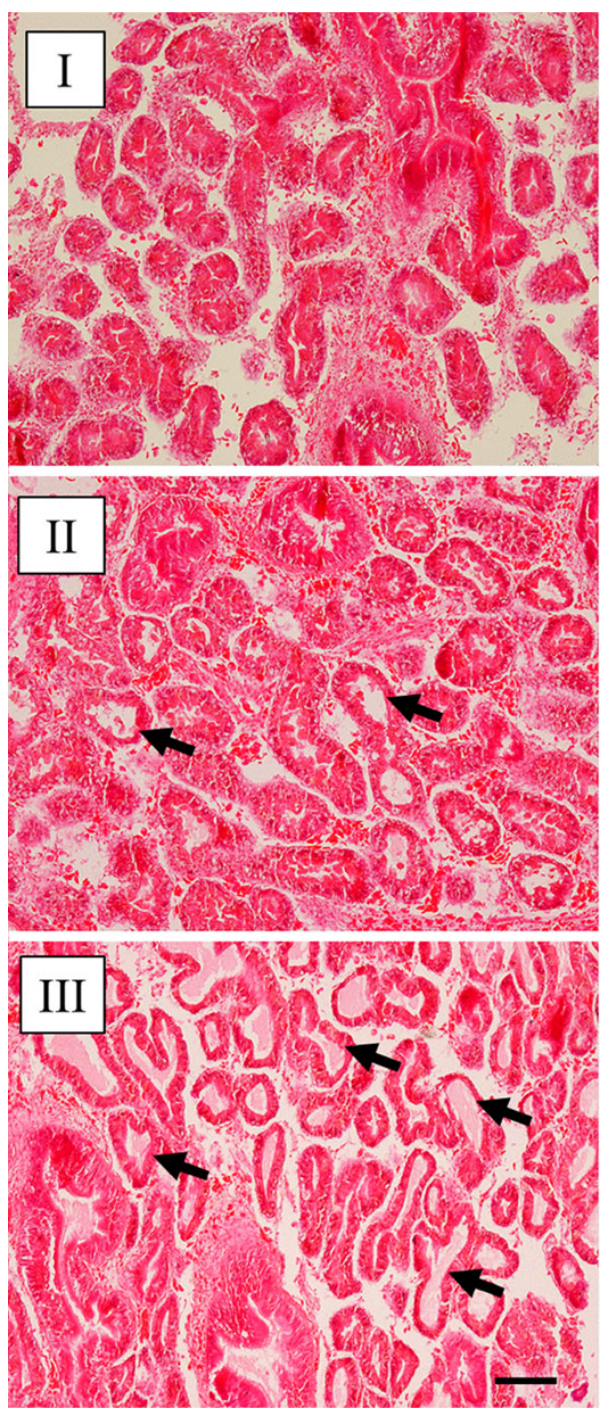

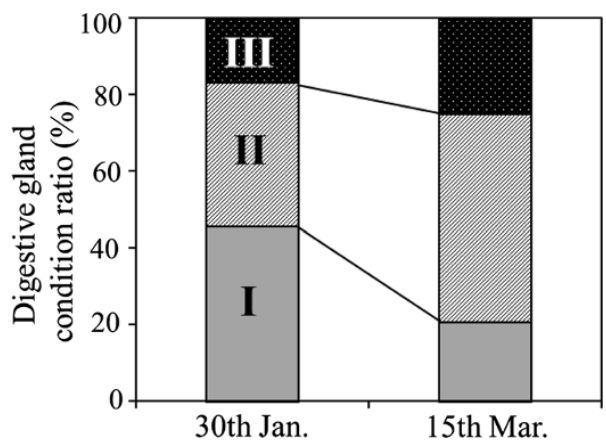

because the environment has already changed. In addition, if the physiological state of the affected organisms is surveyed after a mass mortality event, the main causative factor is not clear in terms of whether the mortality is due to external environmental factors or internal physiological ones.

In this study, we collected biological and environmental data to clarify the cause of a mass mortality event that occurred in a blood cockle aquaculture ground in the Selangor region of Malaysia in mid-February, 2012. The shell length results also supported the occurrence of the mass mortality event in mid-February, because 
Fig. 6 Microphotographs of the digestive duct of blood cockles, Anadara granosa, collected at aquaculture grounds along Selangor coast in late-January and mid-March, 2012. a The duct is filled with food. b The duct is empty (asterisk). Scale bar represents $100 \mu \mathrm{m}$
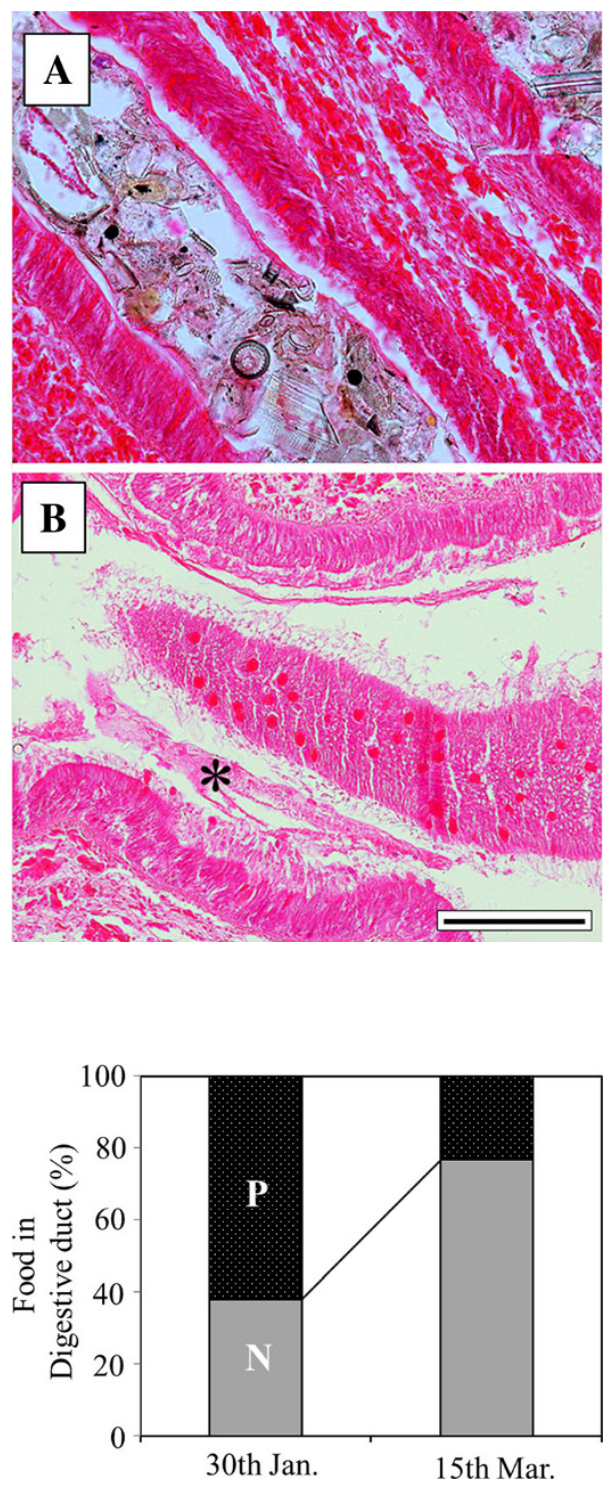

Fig. 7 Ratios of presence of food in the digestive duct of blood cockles, Anadara granosa, collected at an aquaculture ground along Selangor coast in late-January and mid-March, 2012. $P$ Presence. $N$ Non presence

Table 2 Environmental data collected in an aquaculture ground on the sampling dates in late-January and mid-March, 2012

\begin{tabular}{|c|c|c|c|c|c|c|c|}
\hline \multirow[t]{2}{*}{ Date } & \multirow[t]{2}{*}{ Depth (m) } & \multicolumn{4}{|l|}{ Water quality } & \multicolumn{2}{|c|}{ Sediment quality } \\
\hline & & $\begin{array}{l}\text { Temperature } \\
\left({ }^{\circ} \mathrm{C}\right)\end{array}$ & $\begin{array}{l}\text { Salinity } \\
\text { (PSU) }\end{array}$ & $\begin{array}{l}\mathrm{DO} \\
(\mathrm{mg} / \mathrm{L})\end{array}$ & $\begin{array}{l}\text { Chl- } a \\
(\mu \mathrm{g} / \mathrm{L})\end{array}$ & $\begin{array}{l}\text { ORP } \\
(\mathrm{mV})\end{array}$ & $\mathrm{PH}$ \\
\hline 30th Jan., 2012 & 2.5 & 29.7 & 29.9 & 5.1 & 5.2 & $118 \pm 59$ & $7.5 \pm 0.2$ \\
\hline 15th Mar., 2012 & 2.7 & 29.1 & 29.5 & 5.0 & 4.6 & $66 \pm 32$ & $7.4 \pm 0.2$ \\
\hline
\end{tabular}

$D O$ dissolved oxygen, $C h l-a$ chlorophyll- $a, O R P$ oxidation-reduction potential, $p H$ potential hydrogen, mean \pm SD in Sediment quality

both shell length histograms of the living individuals in late-January and the dead individuals in mid-March were approximately the same. Thus, this result suggests that the dead individuals spawned while they were alive. Additionally, it became clear that many individuals had fed poorly in mid-March and that the blood cockles were in the spawning season when this mass mortality event occurred. Among the survived individuals in mid-March, we observed a phenomenon that epithelial cells in the digestive tube were flattened in severe cases; it is suggesting the blood cockles had a no feeding period caused both physiological and 
Fig. 8 Data on daily rainfall in the Selangor region from January to March, 2012. Data are from the Water Resources Management and Hydrology Division, Department of Irrigation and Drainage, Malaysia

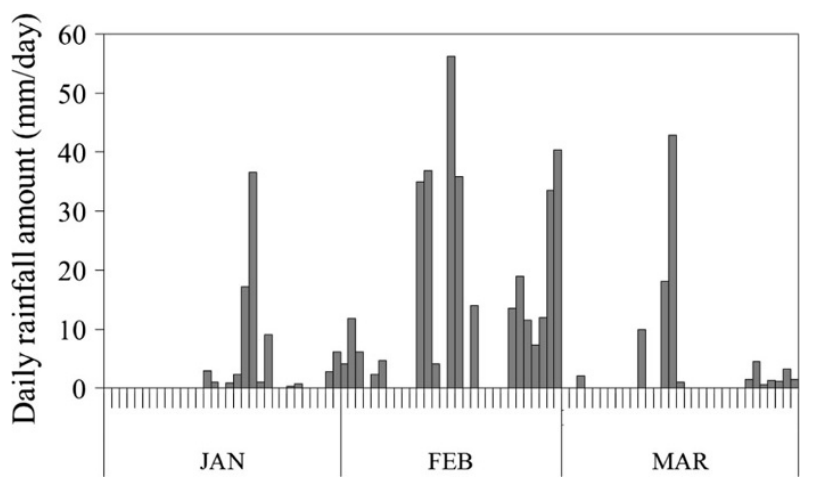

environmental factors (Ellis et al. 1998), and there was a high probability that nutrient absorption was difficult by the histological condition, so even in such individuals who had fed well recently. On the other hand, certain parasites, such as Nematopsis sp., trematode sporocysts, and Turbellaria, were reported to have been isolated from blood cockles along the coast of the Malacca Strait by Uddin et al. (2011). However, in the present study, no parasitic infections were found in the observed tissues in the gonads, digestive gland, mantle, and gill. Therefore, we considered it unlikely for parasitism to be related to the mass mortality event. In addition, we considered improper functioning of those tissues to be unlikely to be related to this event. Furthermore, abnormal water quality, such as the occurrence of a high water temperature, low salinity, and hypoxic water, was not observed in the aquaculture ground during the field surveys. The chlorophyll- $a$ content was also appropriate for bivalves, which indicates that phytoplankton was present during the studied periods.

There was also no observed decrease in $\mathrm{pH}$ level due to the decomposition of organic matter, as shown by the $\mathrm{pH}$ measurement of surface mud, and the redox potential in the mud was also in the oxidation state, so we considered that the aquaculture ground was an appropriate environment for blood cockles. However, to characterize the environment of fisheries, since water quality is more likely to change over a short period than sediment, it is necessary to consider the changes in water quality on a day-to-day basis. In this study, from the daily rainfall data, it became clear that intensive precipitation of over $30 \mathrm{~mm} /$ day occurred on four days in mid-February.

As for other weather-related factors, using a weather report for Subang Jaya, which is located close to Selangor (WeatherSpark 2013), as a reference, we confirmed that there were no extreme weather events, such as high temperature, drought, or strong winds, in late-January to mid-March. This suggested that sediment disturbance caused by strong winds, high water temperature or reduction of the water level due to drought, or a long period of high temperature was unlikely to be causative factors; however, a decrease in salinity caused by flooding from nearby rivers due to heavy rainfall did occur in mid-February, when this mass mortality event occurred. It seems highly likely that such rainfall, even though we could not determine the salinity levels by a regular survey, would have had a large environmental impact via a large amount of fresh water flowing into the aquaculture ground from nearby rivers because of its location near an estuary.

Normally, blood cockles exhibit resistance to low salinity. For example, from a salt-resistance experiment on blood cockles by Davenport and Wong (1986), the cockles showed a clear shell-closing reaction upon exposure to salinity of less than $19 \mathrm{PSU}$; about $50 \%$ of them survived at salinity of $16 \mathrm{PSU}$, while the mortality rate was $100 \%$ upon exposure to salinity of lower than 10 PSU for a week. Therefore, mass mortality of blood cockles is extremely likely upon exposure to a low-salinity environment of lower than 10 PSU for a week or more, which affects the filtering activity that cockles can exhibit at a salinity level of 16-19 PSU.

In this study, the salinity changes at the aquaculture ground during the mass mortality event are unknown because we did not measure this variable. However, it is highly likely that a reduction in salinity due to flooding occurred because there was precipitation of over $30 \mathrm{~mm} /$ day on four days in mid-February, as shown by the weather data. However, to explain this mass mortality event of blood cockles, multiple factors should be considered. Normally, in the spawning season, bivalves have lower environmental resistance, which is known to be potentially associated with death due to even weak environmental stress (Cho and Jeong 2005). Thus, even though the salinity decrease in the aquaculture ground alone may not have been sufficiently severe 
to kill the blood cockles, we should consider the possibility that the spawning season made these organisms particularly susceptible. In addition, from observation of the digestive gland tissue, many of the blood cockles collected in mid-March had no food in the digestive duct, and the epithelial cells in the tubes were also flattened. Thus, it is suggested that the state of the digestive gland made it difficult to absorb nutrients. As such, it is suggested that the blood cockles cultured in the Selangor region were debilitated by reproductive activity, and died due to a feeding disorder that was also influenced by low salinity due to the flooding in midFebruary.

\section{Conclusions}

A mass mortality event of blood cockles occurred in an aquaculture ground in Selangor in mid-February, 2012. The mortality rate was estimated to be $30 \%$ over upon comparison of the data from the two surveys in late-January and mid-March, and blood cockles were shown to be in the spawning season at this time of year. Many individuals collected in mid-March were also in a state of poor feeding. In addition, precipitation data showed four days on which there was rainfall of over $30 \mathrm{~mm} /$ day in mid-February, so the blood cockle aquaculture ground close to an estuary was considered to have been adversely impacted by flooding from nearby rivers. These results suggest that some individuals had been debilitated by reproductive activity, which led to their death upon low food availability due to low salinity and related environmental changes caused by flooding.

Acknowledgments This study was supported in part by the Japan International Research Center for Agricultural Sciences.

Conflict of interest The authors declare that they have no competing interests.

Author's contributions T Yurimoto designed the study, collected and analyzed data and drafted the manuscript. F Mohd Kassim assisted the field sampling and collected environmental data. R Fuseya advised the study and discussed data. A Man organized the field survey and the study. All authors read and approved the final manuscript.

Open Access This article is distributed under the terms of the Creative Commons Attribution License which permits any use, distribution, and reproduction in any medium, provided the original author(s) and the source are credited.

\section{References}

Cho SM, Jeong WG (2005) Spawning impact on lysosomal stability of the Pacific Oyster, Crassostrea gigas. Aquaculture 244:383-387

Davenport J, Wong TM (1986) Responses of the blood cockle Anadara granosa (L.)(Bivalvia: Arcidae) to salinity, hypoxia and aerial exposure. Aquaculture 56:151-162

Ellis MS, Barber RD, Hillman RE, Kim Y, Powell EN (1998) Histopathology analysis-Sampling and analytical methods of the national status and trends program Mussel watch project (ed. Lauenst GG and Cantillo AY). NOAA technical memorandum NOS ORCA 130:199-226

Faulkner P (2010) Morphometric and taphonomic analysis of granular ark (Anadara granosa) dominated shell deposits of Blue Mud Bay, northern Australia. J Archaeol Sci 37:1942-1952

Imai T, Mori K, Sugawara Y, Tamate H, Oizumi J, Itikawa O (1969) Studies on the mass mortality of oysters in Matsushima Bay VII. Pathogenetic investigation. Tohoku J Agric Res 19:250-265

Maeno Y, Yurimoto T, Nasu H, Ito S, Aishima N, Matsuyama T, Watanabe Y (2006) Virus-like particles associated with mass mortalities of the pen shell Atrina pectinata in Japan. Dis Aquat Org 71:169-173

Nagasoe S, Yurimoto T, Suzuki K, Maeno Y, Kimoto K (2011) Effects of hydrogen sulfide on the feeding activity of Manila clam Ruditapes philippinarum. Aquat Biol 13:293-302

Nakamura Y (2005) Suspension feeding of the ark shell Scapharca subcrenata as a function of environmental and biological variables. Fish Sci 71:875-883

Nakao S, Nomura H, Statar MKBA (1989) Macrobenthos and sedimentary environments in a Malaysian intertidal mudflat of the cockle bed. Bull Fac Fish Hokkaido Univ 40:203-213

Narashimham KA, Selvaraj GSD, Lalitha-Devi S (1984) The molluscan resources and ecology of Kakinada Bay. Mar Fish Inf Serv, Tech Ext Ser 59:1-16

Suzuki K, Kiyomoto S, Koshiishi Y (2012) Effects of Periodic Hypoxia on Nutritional Condition and Tolerance of Hypoxic Conditions in the Short-neck Clam Ruditapes philippinarum. J Fish Technol 5:39-47

Tomaru Y, Kawabata Z, Nakano S (2001) Mass mortality of the Japanese pearl oyster Pinctada fucata martensii in relation to water temperature, chlorophyll a and phytoplankton composition. Dis Aquat Org 44:61-68 
Uddin MJ, Yasin Z, Khalil M, Shau-Hwai AT (2011) Parasites of blood cockle (Anadara granosa Linnaeus, 1758) from the Straits of Malacca. J Shellfish Res 30:875-880

WeatherSpark (2013) Historical weather for 2012 in Subang Jaya, Malaysia (http://weatherspark.com/history/34046/2012/ Subang-Jaya-Selangor-Malaysia). p.1-9

Watanabe K (2009) Coastal-zone use of Bandon bay: Area Study in SuratThani province, South Thailand. Kyoto Working Papers on Area Studies. G-COE Series 68: 1-12

Yurimoto T, Mori Y, Ito S, Maeno Y (2008) Reproductive cycle of the subcrenated ark shell Scapharca kagoshimensis (Tokunaga, 1906) in Ariake Bay, Japan. J Shellfish Res 27:1101-1108

Yurimoto T, Kassim FM, Man A (2014) Sexual maturation of the blood cockle, Anadara granosa, in Matang mangrove estuary, Peninsular Malaysia. Int J Aquat Biol 2:115-123 